\title{
Toxicological profile of Grewia bicolor root extract
}

\author{
Maisa Shamoun Ibrahim \\ Department of pharmacology, College of pharmacy/Omdurman Islamic University, Sudan
}

\begin{abstract}
In recent years, traditional system of medicine has become a topic of global importance. Many of the plant species that provide medicinal herbs have been scientifically evaluated for their possible medicinal, pharmacological and toxicological effects. A number of species of the genus Grewia have been used as medicinal herbs to treat several diseases in different parts of the globe. Grewia bicolor is the most famous medicinal plant among the genus Grewia. Despite the wide use of the plant in traditional medicine, so far no scientific evaluation was carried out on this plant for the preclinical toxicity profile. The present study was conducted to evaluate the safety of Grewia bicolor root extract. The plant extract proved that it is relatively safe through the acute and sub-acute studies.
\end{abstract}

Keywords: Traditional medicine, Grewia bicolor, acute toxicity, sub-acute toxicity, Grewia spp.

\section{Introduction}

In folk medicine, the genus Grewia spp extract and preparations from various species exhibited various biological effects, e.g. antioxidant, anti-bacterial and analgesic effects. Also, they used as haemostatic agents and in the treatment of kidney diseases [1,2]. Grewia bicolor plant and seeds are considered to be one of the popular medicinal herbs used in tropical Africa, Ethiopia and Somalia; Eastern Africa, Namibia, Botswana, South Africa and Swaziland. It is also available on coastal areas of Benin and Togo, Yemen, Arabian Desert and India [3]. Grewia bicolor is a part of Sudanese traditional medicine. The plant is used for treating postulant skin lesions and sometimes as a tranquilizer [4]. The plant also is used to treat and manage diarrhea in many areas of Africa [5]. Mohamed, et al., [6] reported that the intraperitoneal administration of the ethanol extract of Grewia bicolor root at a dose of $400 \mathrm{mg} / \mathrm{kg}$ to rats in late pregnancy was lethal to all mother rats.

\subsection{Plant material:}

\section{Materials and Methods}

Grewia bicolor roots were purchased from its natural homeland at Kurdufan Province, southwest Sudan. The plant was authenticated by Taxonomy Department of Medicinal and Aromatic Plant Research Institute, National Center for Research, Khartoum, Sudan. The roots were then washed and allowed to dry in shade for 7 days. The dried plant material was crushed with a manual grinder into a fine powder. Ethanolic extraction process was followed according to [7].

$100 \mathrm{~g}$ of the grounded roots were transferred to a round bottom flask and macerated in $80 \%$ ethanol. The flask was stoppered and left for 24 hours at room temperature. The extract then filtered using sterile cotton pieces. The filtrate thus obtained was concentrated under reduced pressure and the solvent recalled was used to extract the mark following the same procedure till exhaustion. The concentrated extract was collected and left to dry at room temperature till constant weight was obtained. The extract was then kept in a refrigerator for experimentation.

\subsection{Experimental animals:}

Adult male, Wistar Albino Rats (WAR), weighting 110-125 g were housed in standard cages under controlled temperature condition $\left(25^{\circ} \mathrm{C}\right)$ and relative humidity $(40 \%)$ with a $12 \mathrm{~h}$ light cycle beginning at $7 \mathrm{am}$. The rats were provided with standard diet (laboratory rodent's chow) and tap water. All experiments were carried out between 8 am and 12 noon. This study was approved by the Scientific Research Committee of the College of Pharmacy, Omdurman Islamic University (OIU) in accordance with good clinical practice and international guidelines for animal use in experimentations.

2.3. Acute toxicity study: Determination of the maximum tolerated dose, toxic dose and median lethal dose $\left(\mathrm{LD}_{50}\right)$ of the tested extract:

Acute toxicity study was designed according to the method adopted by $[8,9]$. The maximum tolerated dose, the toxic dose and the median lethal dose of the plant's extract was determined by $\mathrm{i} / \mathrm{p}$ administering of the extract in escalating dose levels of 100, 200, 400, 800, 1600, 3200 and $6400 \mathrm{mg} / \mathrm{kg}$.

40 healthy adult males Wister Albino Rats weighting 120-130g were allotted to 8 groups, 5 animals in each. Group 1 received $10 \mathrm{ml} / \mathrm{kg}$, i.p. normal saline and served as negative control. 
The extract was given to seven groups as a single dose of the previous tested doses. The animals were observed continuously for 2-24 hours with regard to the behavioral and neurological profiles. The final $\mathrm{LD}_{\mathbf{5 0}}$ value was calculated. Survival and mortality rates were recorded for each dose as well as the behavioral and neurological signs were also recorded. Thus, the required doses were defined.

\subsection{Sub-acute toxicity:}

Sub-acute toxicity study protocol was adapted from [10]. 10 healthy males Wister Albino Rats weighting 120-130g were allotted to 2 groups, 5 animal in each. Group 1 received 10ml/kg, i.p normal saline for 28 days and served as negative control, groups 2 received G. bicolor root extract at dose level of $800 \mathrm{mg} / \mathrm{kg}$ i.p for 28 days. The animals were sacrificed on day 29. Body weights were recorded at day 0, 14, 21 and 28 post the dose administration for the three groups.

Blood samples were collected from the common carotid artery into a heparinized tubes for hematological studies. Parameters such as hemoglobin $(\mathrm{Hb})$ red blood cell (RBC) count, packed cell volume $(\mathrm{PCV})$ and then the values of mean corpuscular volume (MCV), mean cell hemoglobin $(\mathrm{MCH})$ and the mean corpuscular hemoglobin concentration (MCHC), white blood cells (WBC), Neutrophils, Eosinophils, Basophils, Lymphocytes and Monocytes were calculated.

The serum was separated for determining the concentrations of biochemical parameters like blood urea nitrogen (BUN), creatinine, sodium, potassium, total protein, albumin, alanine aminotransferase (ALT) and alkaline phosphatase (ALP).Variations in body weight were monitored during the test period.

After the blood collection livers and kidneys were removed from all rats for detection of gross lesions. All tissues were fixed in $10 \%$ buffered formalin solution. After routine processing, the paraffin sections of each tissue were cut at $5 \mu \mathrm{m}$ thickness and stained with haematoxylin and eosin for a microscopic examination.

\subsection{Statistical analysis:}

The values are expressed as mean \pm SEM (Standard Error of Mean) and the data were analyzed using one way ANOVA followed by Tukey-Krammer test. The level of significance was set at $\mathrm{p}<0.05$. Median anticonvulsant dose $\left(\mathrm{ED}_{\mathbf{5 0}}\right)$ was calculated according to the method of [11]. A computer program was used to calculate $95 \%$ confidence limit (C.L 95\%) of $\mathrm{ED}_{\mathbf{5 0}}$.

\section{Results}

\subsection{Acute toxicity study: Determination of the maximum tolerated dose, toxic dose and median lethal} dose $\left(L D_{50}\right)$ of the tested extract:

The data revealed that the plant extract was well tolerated in rats up to the dose of $800 \mathrm{mg} / \mathrm{kg}$, i.p without lethality or toxic signs during $24 \mathrm{~h}$ post the dose administration. No mortality was observed during 14 days post the treatment with the tolerated dose. Behavioral signs of toxicity were exhibited by rats that received $1600 \mathrm{mg} / \mathrm{kg}$ and above such as increase in respiratory rate, increased abdominal contractions, deep depression and indifference. Also, neurological signs were observed such as paralysis of the hind limbs, writhing, abnormal gait and deformity in shape. These behavioral and neurological signs disappeared with in $24 \mathrm{~h}$ of the extract administration. $60 \%$ mortality occurred post 60-240 minutes of the administration of the dose $3200 \mathrm{mg} / \mathrm{kg}$ while $100 \%$ mortality occurred 10-15 minutes post administration of the dose $6400 \mathrm{mg} / \mathrm{kg}$, i.p. The LD50 (median lethal dose) was calculated to be $2663.92 \mathrm{mg} / \mathrm{kg}$. (Table $3.1 .1 \& 3.1 .2$ )

(Table 3.1.1) Acute toxicity study: Determination of the maximum tolerated dose, toxic dose and median lethal dose $\left(\mathrm{LD}_{50}\right)$ of the tested extract:

\begin{tabular}{|c|c|c|c|c|c|c|}
\hline $\begin{array}{l}\text { Extract Dose } \\
\quad(\mathrm{mg} / \mathrm{kg})\end{array}$ & $\begin{array}{l}\text { Mortality } \\
\text { rate }\end{array}$ & $\begin{array}{c}\text { Time of death post } \\
\text { administration/ minutes }\end{array}$ & $\begin{array}{l}\text { Toxic dose } \\
\mathrm{mg} / \mathrm{kg}\end{array}$ & $\begin{array}{l}\text { Lethal dose } \\
\mathrm{mg} / \mathrm{kg}\end{array}$ & $\begin{array}{c}\mathrm{LD}_{50} \\
(\mathrm{mg} / \mathrm{kg})\end{array}$ & C.L 95\% \\
\hline $200-1600$ & $0 \%$ & 0 & \multirow{2}{*}{1600} & \multirow{2}{*}{3200} & \multirow{2}{*}{2663.92} & \multirow{2}{*}{$1582.6-4475.5$} \\
\hline 6400 & $100 \%$ & $10-15$ & & & & \\
\hline
\end{tabular}

(Table 3.1.2) Acute toxicity: Description of the toxicity reflected by behavioral and neurological signs of the tested plant extract:

\begin{tabular}{|c|c|}
\hline Behavioral signs at the toxic dose & Neurological signs at the toxic dose \\
\hline $\begin{array}{c}\text { Deep depression, indifference, increase in } \\
\text { respiratory rate, increase in abdominal contractions. }\end{array}$ & Paralysis at the hind limbs, writhing, abnormal gait \\
\hline
\end{tabular}

\subsection{Sub -acute toxicity study:}

The dose of $800 \mathrm{mg} / \mathrm{kg}$ i.p for 28 days was considered to be the sub toxic dose.

No significant differences either in control group or treated group of plant extract were noticed in body weight as summarized in (Table 3.2.1). The tested dose of extract didn't show any significant changes neither in 
hematological nor in biochemical parameters (hepatic and renal function tests) compared to the control group (Tables 3.2.2 and 3.2.3).

The histopathological sections of livers and kidneys of the tested group exhibited normal architecture on comparison to the control group (Figures 1\&2).

Table 3.2.1. Body weights of rats in sub- acute toxicity of G.bicolor extract:

\begin{tabular}{|c|c|c|c|c|}
\hline Treated groups & \multicolumn{4}{|c|}{ Body weight (g) } \\
\hline & Day 0 & Day 7 & Day 14 & Day 28 \\
\hline Control & $123.00 \pm 4.36$ & $136.00 \pm 4.30$ & $142.67 \pm 6.64$ & $153.00 \pm 4.00$ \\
\hline G.bicolor & $125.00 \pm 6.52$ & $140.00 \pm 1.30$ & $145.67 \pm 3.24$ & $149.00 \pm 4.30$ \\
\hline
\end{tabular}

Values are expressed as mean \pm S.E.M., $\mathrm{n}=5$.

Table 3.2 .2. Effects of 28 days administration of G.bicolor extract in rats

\begin{tabular}{|l|l|l|}
\hline Parameters & \multicolumn{1}{|c|}{ Control group } & G. bicolor group \\
\hline $\mathrm{RBC}\left(\mathrm{x} 10^{6} / \mu \mathrm{l}\right)$ & $6.86 \pm 0.32$ & $6.84 \pm 0.16$ \\
\hline $\mathrm{Hb}(\mathrm{g} / \mathrm{dl})$ & $11.80 \pm 0.30$ & $11.77 \pm 0.34$ \\
\hline $\mathrm{PCV}(\%)$ & $36.23 \pm 1.07 \quad 66$ & $36.70 \pm 0.86$ \\
\hline $\mathrm{MCV}(\mathrm{fl}) *$ & $53.96 \pm 1.43$ & $53.61 \pm 0.72$ \\
\hline $\mathrm{MCH}(\mathrm{pg}) * *$ & $17.60 \pm 0.01$ & $17.22 \pm 0.19$ \\
\hline $\mathrm{MCHC}(\mathrm{g} / \mathrm{dl})$ & $32.56 \pm 0.27$ & $32.10 \pm 0.59$ \\
\hline $\mathrm{WBC}\left(\mathrm{x} 10^{3} / \mu \mathrm{l}\right)$ & $7.27 \pm 1.34$ & $7.59 \pm 1.53$ \\
\hline Neutrophils $(\%)$ & $23.61 \pm 2.13$ & $22.93 \pm 3.74$ \\
\hline Eosinophils $(\%)$ & $1.47 \pm 0.55$ & $1.65 \pm 0.62$ \\
\hline Basophils $(\%)$ & $0.00 \pm 0.00$ & $0.00 \pm 0.00$ \\
\hline Lymphocytes $(\%)$ & $69.82 \pm 6.53$ & $67.96 \pm 6.54$ \\
\hline Monocytes $(\%)$ & $2.00 \pm 0.48$ & $1.46 \pm 0.39$ \\
\hline
\end{tabular}

Values are expressed as Mean \pm S.E.M., $\mathrm{n}=5 .{ }^{*} \underline{\mathrm{fL}}:$ femtoliters $\left(10^{-15} \mathrm{~L}\right), * * \mathrm{pg}:$ pictograms $\quad(=0.06207$ femtomol).

Table 3.2.3. Effects of 28 days administration of G.bicolor root extract on kidney and liver functions in rats:

\begin{tabular}{|l|l|l|}
\hline Parameters & Control group & G. bicolor group \\
\hline Blood urea $(\mathrm{mg} / \mathrm{dl})$ & $37.67 \pm 1.45$ & $34.33 \pm 2.96$ \\
\hline Serum creatinine $(\mathrm{mg} / \mathrm{dl})$ & $0.77 \pm 0.03$ & $0.80 \pm 0.03$ \\
\hline $\mathrm{Na}+(\mathrm{mmol} / \mathrm{L})$ & $147.66 \pm 2.84$ & $144.70 \pm 6.50$ \\
\hline $\mathrm{K}+(\mathrm{mmol} / \mathrm{L})$ & $6.30 \pm 0.20$ & $6.40 \pm 0.05$ \\
\hline Total protein $(\mathrm{g} / \mathrm{dl})$ & $7.83 \pm 0.49$ & $7.80 \pm 0.20$ \\
\hline Albumin $(\mathrm{g} / \mathrm{dl})$ & $4.26 \pm 0.13$ & $4.20 \pm 0.12$ \\
\hline ALT $(\mathrm{U} / \mathrm{L})$ & $30.33 \pm 4.33$ & $26.33 \pm 4.76$ \\
\hline ALP $(\mathrm{U} / \mathrm{L})$ & $104.10 \pm 8.00$ & $92.33 \pm 16.44$ \\
\hline
\end{tabular}

Values are expressed as Mean \pm S.E.M., $\mathrm{n}=5$

Fig.(1): Photomicroscope of liver tissue post 28 days: A. control (N. saline, 10ml $/ \mathrm{kg}$,i.p/day) ; B. G. bicolor (800mg/kg,i.p/day. H\&E X 20.
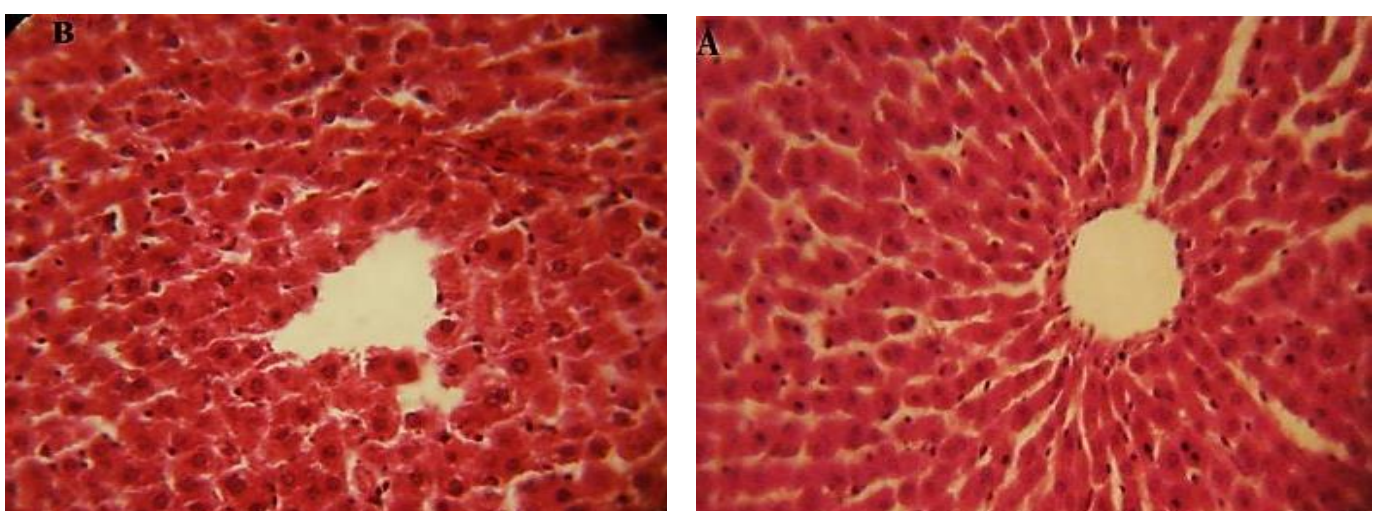
Fig.(2): Photomicroscope of kidney tissue post 28 days: A. control (N. saline, 10ml/kg,i.p/day); B. G. bicolor (800mg/kg,i.p/day. H\&E X 20.
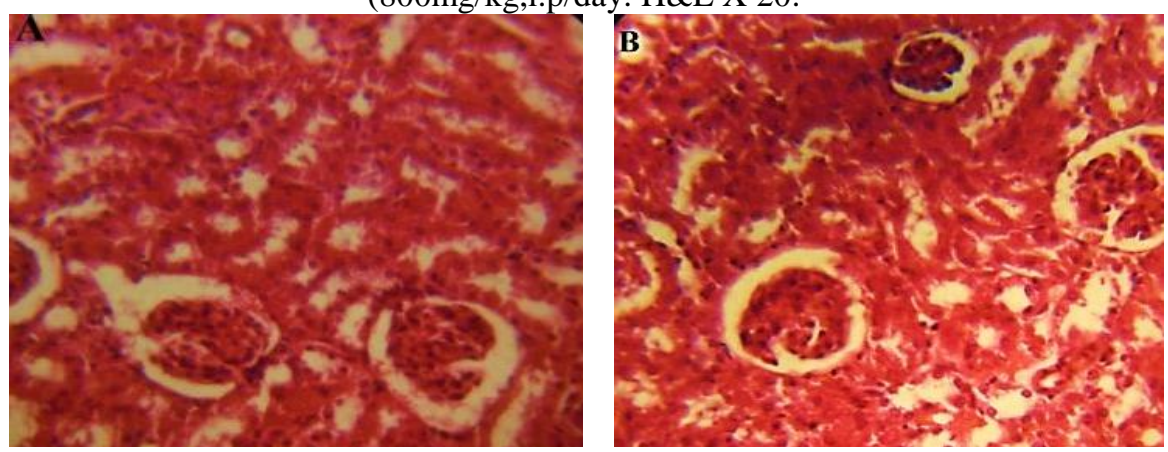

\section{Discussion}

The tolerated dose of G. bicolor extract was found to be $800 \mathrm{mg} / \mathrm{kg}$, ip while the toxic dose was $1600 \mathrm{mg} / \mathrm{kg}$, ip, no deaths were observed but behavioral and neurological toxic signs were recorded such as increase of respiration and abdominal contraction post the treatment with the toxic dose of G. bicolor. This might be related to the presence of serotonin which stimulates the respiration and the abdominal contraction [11, 12]. Regarding to the neurological signs, paralysis at the hind limbs and abnormal gait were observed, these neurological signs suggested to be due to the excessive GABA-ergic chloride channels activation which found to be a strategy for central synaptic neurotransmitter block to induce transient and focal leg paralysis in its host [13]. Writhing also was observed and may be due to the abdominal contraction.

The lethal dose of extract was found to be $3200 \mathrm{mg} / \mathrm{kg}$, i.p. The calculated $\mathrm{LD}_{\mathbf{5 0}}$ value was in the range of $2663.92 \mathrm{mg} / \mathrm{kg}$. These values suggested relatively low toxicity of the extract. Similarly, Ukwuani, et al., [14] reported that the toxic evaluation of the methanolic leaves extracts of Grewia crenata in rats revealed that the lethal dose of this plant was estimated to be more than $5000 \mathrm{mg} / \mathrm{kg}$. Another similar result was reported by [15] who found that the methanolic leaves extract of Grewia hirsuta proved to be safe up to $2000 \mathrm{mg} / \mathrm{kg}$ when orally administered to rats.

In the sub-acute toxicity study, the extract was administered at a dose of $800 \mathrm{mg} / \mathrm{kg}$, i.p for 28 days. No deaths were observed during the study period. The effect of 28 days of administration extract showed no significant change on the animal's body weights. This reveals that it did not adversely affect the basic metabolic processes of the experimental rats.

These results are identical with Wilson, et al., [16] who found that the rats' weights didn't show any significant change after feeding of Grewia mollis stem bark with the normal diet at $10 \%$ for 4 weeks. Also, [17] reported that no significant changes in body weight were observed after the ingestion of Grewia asiatica fruit extract to mice at dose rate of $700 \mathrm{mg} / \mathrm{kg}$ daily for 15 days.

The treated group didn't show any significant changes in hematological and biochemical parameters (hepatic and renal function tests) compared to the control group. Assessment of hematological parameters can be used to determine the extent of the deleterious effect of extracts on the animal blood. It can also be used to explain blood relating functions of a plant extract or its products [14]. Heamogram was estimated for both the treated and the control groups. The results showed no unusual effect on RBCs count, hemoglobin, PCV, MCV, $\mathrm{MCH}, \mathrm{MCHC}$, WBCs count, neutrophils, eosinophils, basophils, lymphocytes and monocytes in treated animals compared with the control group. This indicates that the extract did not affect blood cells and their production.

A similar result reported about the leaf extract of another Grewia spp., G. crenata by Ukwuani, et al., [14] who found that the plant extract didn't show any significant changes in the hemogram of rats that administered a dose range of $900-3600 \mathrm{mg} / \mathrm{kg}$ orally for 28 days.

\section{Conclusion and Recommendations}

- The acute toxicity study showed that the G. bicolor extract is relatively safe.

- Heamatological, biochemical and histological results obtained from the liver and kidney function parameters indicated that the ingestion of $\mathrm{G}$. bicolor root $800 \mathrm{mg} / \mathrm{kg}$ i.p for 28 days had no observable toxic effects on these organs at the tested dose. It was therefore suggested that these results could form the basis for clinical trial in human.

- These results were obtained from experimental animals' models, so these herbal plant should be used in appropriate formulations for further clinical trials in human. 


\section{Acknowledgments}

The author is very thankful to Al-Ahfad University and Department of Medicinal and Aromatic Herb Research Institute, National Council for Research, Khartoum, Sudan for supporting by providing apparatuses and drugs.

\section{References}

[1]. Goyal, K, Phytochemical and pharmacological properties of the genus Grewia: A Review. International Journal of Pharmacy and Pharmaceutical Sciences, 4(4), 2012, 72-78.

[2]. Al-Musayeib, N.M., Mothana, R.A., Matheeussen, A., Cos, P. and Maes, L, In vitro antiplasmodial, antileishmanial and antitrypanosomal activities of selected medicinal plants used in the traditional Arabian Peninsular region. BMC Complementary and Alternative Medicine. 2012.

[3]. Brink, M, Grewia bicolor Juss. (Plant Resources of Tropical Africa) (5 $5^{\text {th }}$ Ed) Wageningen, Netherlands, 2007.

[4]. Jaspers, W.J., Bashir, A.K., Zwerving, J.S. and Malingre, T.M, Investigation of Grewia bicolor Juss. Journal of Ethnopharmacology, 17 (3), 1986, 205-211.

[5]. Semenya, S.S. and Maroyi, A, Medicinal plants used by the Bapedi traditional healers to treat diarrhoea in the Limpopo Province, South Africa, Journal of Ethnopharmacology, 144(2), 2012, 395-401

[6]. Mohamed, A.E, Karrar, M.A, Salih, A.E, Bashir, A.K, Ali, M.B. and Khalid, S.A, Pharmacological activities of Grewia bicolor roots. Journal of Ethnopharmacology, 28 (3), 1990, 285-92.

[7]. Pavia, D.L., Lampman, G.M. and Kriz, G.S. and Engel, R.G, Introduction to Organic Laboratory Techniques: A Microscale Approach ( $3^{\text {rd }}$ Ed) W.B. Saunders Co., Philadelphia,1999, ISBN: 978-0030238482.

[8]. Jalalpure, S.S., Salahuddin, M., Imtiyaz, M. and Manvi, F.V, Anticonvulsant effects of Calotropis procera root in rats. Pharmaceutical Biology, 47(2), 2009, 162-167.

[9]. Lork, D, A new approach to practical acute toxicity testing. Archives of Toxicology, 53, 1983, $275-287$.

[10]. Anupama,T., Manu,C., and Rajesh, S, A 28 days sub-acute toxicity study in Swiss Albino Mice to evaluate toxicity profile of Neurotol Plus (mannitol and glycerol combination). International Journal of Biomedical Science, 5(4), 2009, 428-433.

[11]. Moore, K.E., Milton, A.S. and Gosselin, R.E, Effect of 5-hydroxytryptamine on the respiration of excised lamellibranch gill. British Journal of Pharmacology, 17, 1961, 278-285.

[12]. Kitazawa, T., Ukai, H., Komori, S. and Taneike, T, Pharmacological characterization of 5-hydroxytryptamine-induced contraction in the chicken gastrointestinal tract. Autonomic and Autacoid Pharmacology, 26(2), 2006, 157-68.

[13]. Moore, E.L., Haspel, G., Libersat, F. and Adams, M.E, Parasitoid wasp sting: a cocktail of GABA, taurine and beta-alanine opens chloride channels for central synaptic block and transient paralysis of a cockroach host, Journal of Neurobiology, 66(8), 2006, 81120.

[14]. Ukwuani, A.N., Abubakar, M.G., Hassan, S.W. and Agaie, B.M.Toxicological studies of hydromethanolic leaves extract of Grewia crenata. International Journal of Pharmaceutical Sciences and Drug Research, 4(4), 2012, 245-249.

[15]. Keyur, M., Pharmacological screening of Grewia hirsute. Master thesis, Rajiv Gandhi University of Health Sciences, KarnatakaFaculty of Pharmacy, 2008.

[16]. Wilson, O., Julius, L., Joseph, Z. and Mike, A., Toxic Effects of Grewia mollis stem bark in experimental rats. Journal of American Science. 6 (12), 2010, 1544-1548.

[17]. Sharma, K.V. and Sisodia, R., Radioprotective potential of Grewia Asiatica fruit extract in mice testis. Pharmacology online, 1, $2010,487-495$. 